\title{
The Diversity in Dust Fungal Spores Concentration at Four Districts of Al-Najaf Environment and their Potential Correlation with Asthma
}

\author{
Noor I. Nasser ${ }^{1 *}$ (D), Maysoon K. Al-Hadrawi ${ }^{(D)}$, Salam A. Oleiwi ${ }^{2}$ and \\ Ahmed Abdulhasan Mohsin ${ }^{3}$ \\ ${ }^{1}$ Department of Pathological Analysis, ${ }^{2}$ Department of Technical Nursing, ${ }^{3}$ Department of Community Health, Kufa \\ Technical Institute, Al-Furat Al-Awsat Technical University, Kufa - 31001, Al-Najaf, Iraq.
}

\begin{abstract}
Fungal spores are biological molecules that are widespread in the indoor and outdoor air. Several types of the very common fungal spores are known as allergens, with the potential to cause respiratory illnesses by increasing the aggravation of asthma and rhinitis. From January to December 2018 , a crosssectional environmental survey was performed to determine the dust fungal spore concentration in four district of Al-Najaf governorates and examine the potential correlation between the concentration of fungal spores and the numbers of patients have asthma, also the effect of some demographical characteristic on the percentage of asthma. Fungal spores in dust were collected using Achudume method, the samples were cultured at room temperature for 7-10 days, the identification and counting of fungi were performed. The data of patients have asthma was obtained from statistics division at hospitals and health centers located in these districts. The result of this study revealed the highest fungal spore concentration was in the dust of Kufa district (29\%), moreover, the most prevalent fungal isolate from the dust belonged to the genus Aspergillus, Alternaria, Cladosporium, and Penicillium. There was a remarkable difference among the four districts regarding the type and concentration of fungal spores. There was a significant positive correlation between the number of patients have asthma and the concentration of fungal spores in dust $\left(r_{p}=0.96, p\right.$-value $\left.=0.0001\right)$. The overall percentage of asthma in the study population was $4.1 \%$, the rate of asthma appear to be more prevalent among male than female $(2.47 \%$ vs $1,67 \%)$, there was no difference between the percentage of asthma in urban and rural areas $(2.2 \%, 1.9 \%)$, and it was statistically non-significant at $\leq \mathbf{0 . 0 5}$. There was a medium direct correlation between age groups and asthma $\left(r_{p}=0.687\right)$ towered the increase in age, but it was not statistically significant $(P=\mathbf{0 . 1 3 2})$. It was clear that most of the recorded fungal spore type have allergenic properties, which mean that increase their concentration in the environment of AL-Najaf can negatively effect on the status of patients have asthma.
\end{abstract}

Keywords: Dust, Fungi, Asthma, Allergen, Urban.

*Correspondence: kin.nor@atu.edu.iq

(Received: 02 July 2019; accepted: 03 December 2019)

Citation: Noor I.Nasser, Maysoon K. Al-Hadrawi, Salam A. Oleiwi and Ahmed Abdulhasan Mohsin, The Diversity in Dust Funga Spores Concentration at Four Districts of Al-Najaf Environment and their Potential Correlation with Asthma, J Pure Appl Microbiol. 2019; 13(4):2169-2176. https://doi.org/10.22207/JPAM.13.4.29

(C) The Author(s) 2019. Open Access. This article is distributed under the terms of the Creative Commons Attribution 4.0 International License which permits unrestricted use, sharing, distribution, and reproduction in any medium, provided you give appropriate credit to the original author(s) and the source, provide a link to the Creative Commons license, and indicate if changes were made. 


\section{INTRODUCTION}

Asthma can be defined as a complex inflammatory disease of the airway, Characterized by bronchial hyperplasia. Several family studies estimated that genetic factors have a relative contribution with atopic and asthma, it is possible to reach $40 \%-60 \%$. While further studies conducted that asthma was not just a genetic disease but it was a disease result from the interaction of multiple genetic and environmental factors ${ }^{1}$. Asthma may be affected by several potential risk factors such as regional differences, gender differences, stressful lifestyle, smoking, microbial dust and allergens etc. ${ }^{2,3}$. Asthma could result from inhalation of allergens, while atopic asthma also could result from the body's interaction with allergen outside of the lung ${ }^{4}$. Filamentous fungi are common aeroallergens patients represented a major part of the bioaerosol, it was also called molds which consist mainly of three phyla; Zygomycota, Ascomycota, and Deutromycota. Phyla of these molds have different way of reproduction; furthermore each species have the ability to make several kinds of spores that could be sexual and asexual. These spores and conidia resist dryness for several years. Fungi were producing a huge amount of spores that could be transmuted by dust across a vast distance. Enormous correlative evidence proposes an association between fungi and asthma, that may be triggered from the elevated in the numbers of airborne fungal spores ${ }^{5,6}$.

\section{MATERIAL AND METHODS Location}

This research was carried out in the city of AL-Najaf governorate, which includes four county and seven districts. To facilitate the collection and study of dust samples we divided these districts into four regions, north, south, east and west. Time

Samples and data were collected monthly from January to December of 2018.

\section{Samples and Data Collection}

There was no international accepted recommendation standard method for sampling dust fungal spores, however in this study, we used two methods for sample collection from all locations have been chosen. The first method by using a petri dish $(26 \mathrm{~cm}$ diameter) was placed near the most used roads of these districts for $12 \mathrm{hr}$. Dust samples were summed together, sieved and collect carefully to obtain at least $1 \mathrm{~g}$ of dust. The dust samples were stricken on agar plat for farther counting and identification?. The Second method by using a Petri-plate containing agar medium (SDA) was exposed face upwards to the environment to collect particles settling by gravity (gravity settle plate techniques), in the same location for ( $\mathrm{hr}$ ) then incubated at room temperature for 5-7 days ${ }^{8}$. Data of patients with asthma have been obtained from records of statistics division in health centers and hospitals of the governorate. Only the first visits of each patient have been included in the data of this study.

\section{Sample Processing}

We use plate count technique for enumerating the fungi spore in dust samples. A stander fungal identification technique was used, such as observation of growth characteristics, cellular or spore morphology, and biochemical test for identification of fungi that exist in each area ${ }^{8,9}$.

\section{Statistical Analysis}

Data analysis using SPSS version 18 software, categorical variable were presented as frequencies, percentage and Pearson chi-square, P-value of $\leq 0.05$ was considered as statistically significant. Continuous variables were presented as mean, standard deviations and Pearson correlation coefficient to determine the association between fungal spore in dust and asthma, P-value of $\leq 0.01$ was considered as statistically significant. The logtransformed measurements for the concentration of fungal spore in dust and the number of asthma cases were used in statistical analyses.

\section{RESULTS}

Environmental factors such as temperature, humidity and the rate of wind speed varies from place to place. These factors have a great impact on the reproduction rate of fungal spore. Kufa had a higher fungal spore's percentage (29\%) compared to Meshgap (25.4\%), Najaf (24.9\%), and Manathera (20.7). Aspergillus Niger spores is the predominant spores type in Al-Najaf governorate (15.7\%), the highest percentage of A. niger spores was at meshgap (5.2\%) and Najaf city(3.9\%), followed by Alternaria which represent 
the second dominant spore type (13.8\%), with the highest percentage at Kufa city $(4.7 \%)$, while A. nidulans spores represent the third prevalent spore type (12.1\%) with the highest percentage in Manathera (3.8\%) as shone in Fig. 1.

The highest log-fungal spore concentration was in March (8.4456 CFU \g), there were also three other peaks found in April, October and November with $(8.2949,8.206$, $8.0212 \mathrm{CFU} \backslash \mathrm{g}$ ) respectively, while the lowest log- fungal spore concentration was recorded in January (7.1717 CFU \g). Regression analysis $(y=0.04 x+7.4972),\left(R^{2}=0.0862\right)$ for monthly fungal spore concentration indicates very weak non- significant correlation $\left(r_{p}=0.29\right),(p=0.1)$ as shown in Table 1 and Fig. 2.

Asthma is a widespread disease that affects millions of adults and children. It is diagnosed annually in an increasing number of people. The cause of this increase is not known exactly, but it is clear that genetic and environmental factors have a role in increasing the prevalence of asthma. This study performed to determine the potential relationship between the concentration of fungal spore in dust and the number of asthmatic patients who attended hospital and health centers during a full 12 months. In order to find out the correlation between the

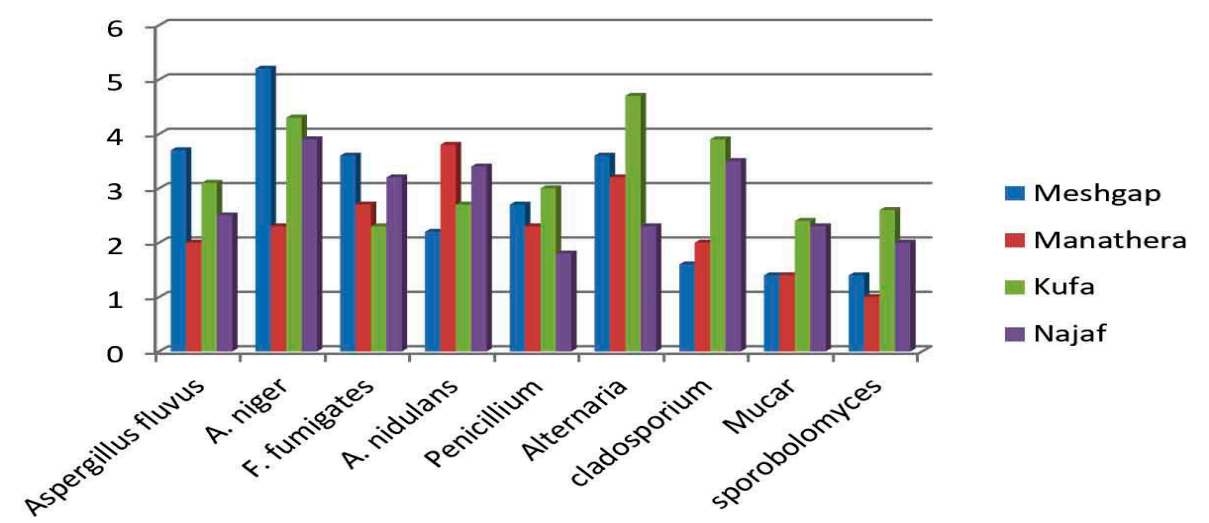

Fig. 1. The type and percentage of fungal spore distributed according to districts

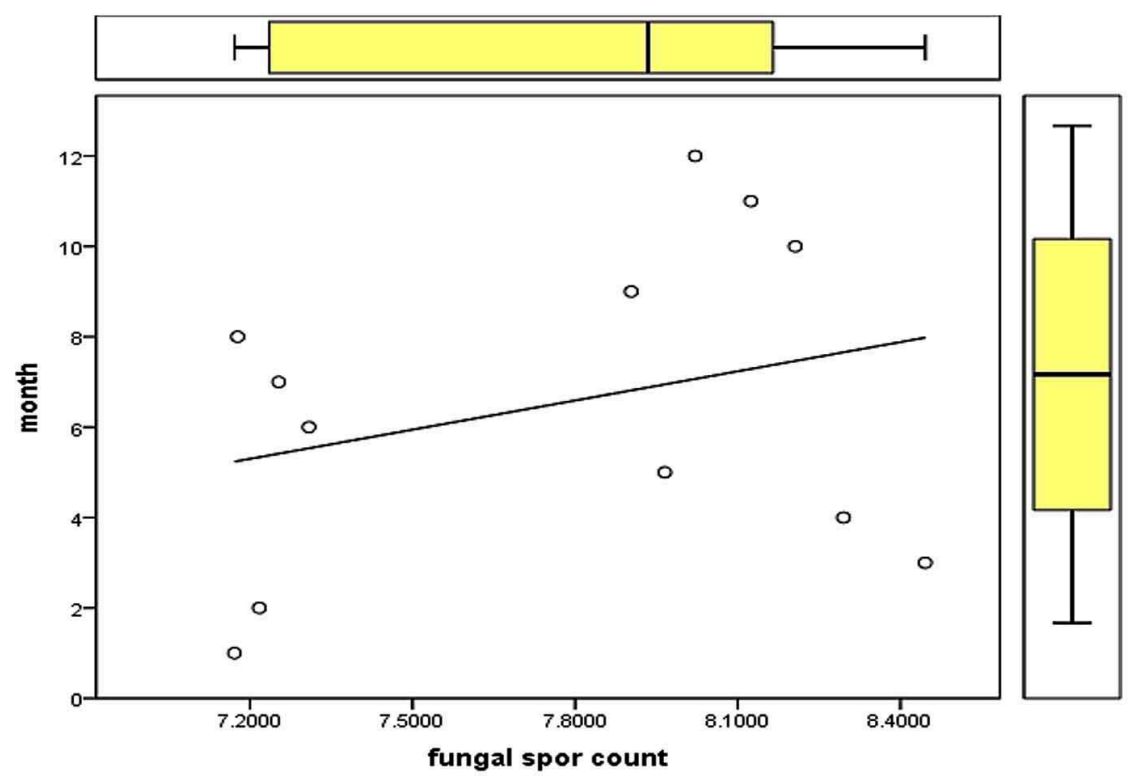

Fig. 2. Monthly distribution of log-fungal spore's concentration in dust 
Table 1. Correlation between fungal spore count in dust and the number of patents has asthma

\begin{tabular}{|c|c|c|c|c|}
\hline Parameter & & Months & Fungal spore & Asthma \\
\hline \multirow[t]{2}{*}{ Months } & Person correlation & 1 & 0.294 & 0.015 \\
\hline & Significant & & 0.177 & 0.482 \\
\hline \multirow[t]{3}{*}{ Fungal spore } & Person correlation & 0.294 & 1 & 0.943 \\
\hline & Significant & 0.177 & & $0.0001^{*}$ \\
\hline & \multicolumn{2}{|c|}{ Mean $\pm S D$} & $7.7 \pm 0.4$ & \\
\hline \multirow[t]{3}{*}{ Asthma } & Person correlation & 0.15 & 0.943 & 1 \\
\hline & Significant & 0.482 & $0.0001^{*}$ & \\
\hline & & & Mean $\pm S D$ & $2 \pm 0.2$ \\
\hline
\end{tabular}

* Correlation is significant at 0.01 level.

variables, Pearson's correlation coefficients have been used. In this study the results reveal a significant strong positive correlation $\left(r_{p}=\right.$ 0.94), ( $P=0.0001)$ between the concentration of fungal spore in dust and the number of patients with asthma as showed in Table 1, also there was a linear regression between fungal spore concentration and number of patients with asthma( $y=1.8833 x+3.864),\left(R^{2}=0.8894\right)$ as shown in Fig. 3.

Out of 39579 patients who attended the hospitals and health centers during the study period, only $4.1 \%$ have asthma, from which $2.47 \%$ male and $1.67 \%$ female, these differences were statistically non-significant at $\leq 0.05$. Moreover, there was no difference between the percentage of asthma in urban and rural areas (2.2\%, 1.9\%), it was statistically non-significant at $\leq 0.05$ as showed in Table 2. The maximum percentage of asthma cases was among patients with age above 50 years (32.2), followed by (15.5\%) for each very young children smaller than 10 years and patients between age (41-50) years, $(14.2 \%)$ in patients between age (31-40) and (12\%, 10.2\%) for patients with age groups(21-30, 11-20) as revealed in Fig. 4. There was a medium direct correlation between

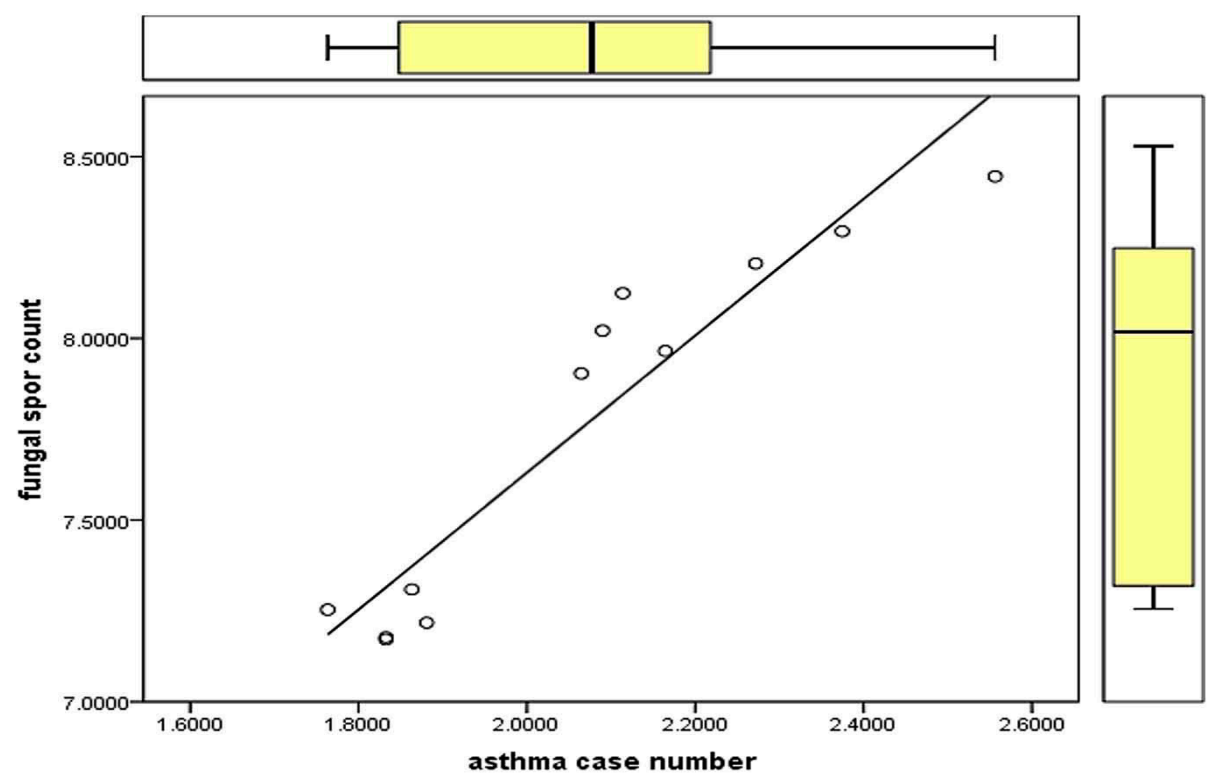

Fig. 3. Simple linear regression between log-fungal spores count in dust and the log-number of patients has asthma 
Table 2. Demographic characteristics of patients having asthma

\begin{tabular}{|c|c|c|c|c|}
\hline \multicolumn{3}{|l|}{ Variable } & \multirow{2}{*}{$\begin{array}{c}\text { No } \\
24706\end{array}$} & \multirow{2}{*}{$\begin{array}{c}\% \\
62.4\end{array}$} \\
\hline \multirow[t]{5}{*}{ Gender } & No of subjects & Male & & \\
\hline & & Female & 13895 & 35.1 \\
\hline & Asthmatics & Male & 978 & 2.47 \\
\hline & & Female & 664 & 1.67 \\
\hline & Total & & 39579 & 100 \\
\hline \multicolumn{5}{|c|}{$X^{2}=21.4>X_{T}^{2}=3.8$ at $\leq 0.05$} \\
\hline \multirow[t]{5}{*}{ Residence } & No of subjects & urban & 21984 & 55.5 \\
\hline & & Rural & 15953 & 40.3 \\
\hline & Asthmatics & urban & 882 & 2.2 \\
\hline & & Rural & 760 & 1.9 \\
\hline & Total & & 39579 & 100 \\
\hline \multicolumn{5}{|c|}{$X^{2}=11.5>X_{T}^{2}=3.8$ at $\leq 0.05$} \\
\hline
\end{tabular}

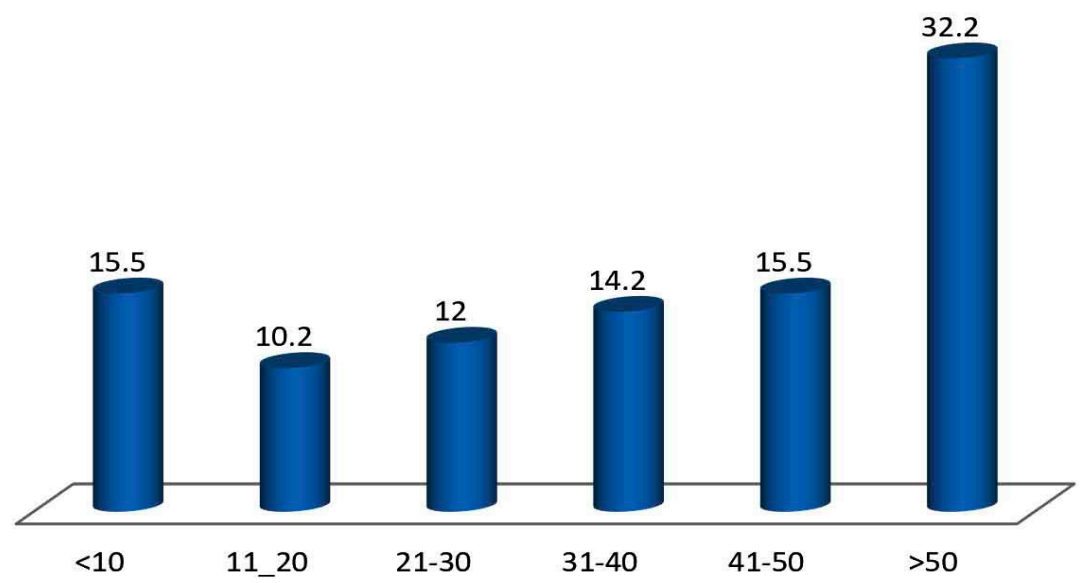

Fig. 4. Percentage of patients has asthma distributed according to age groups

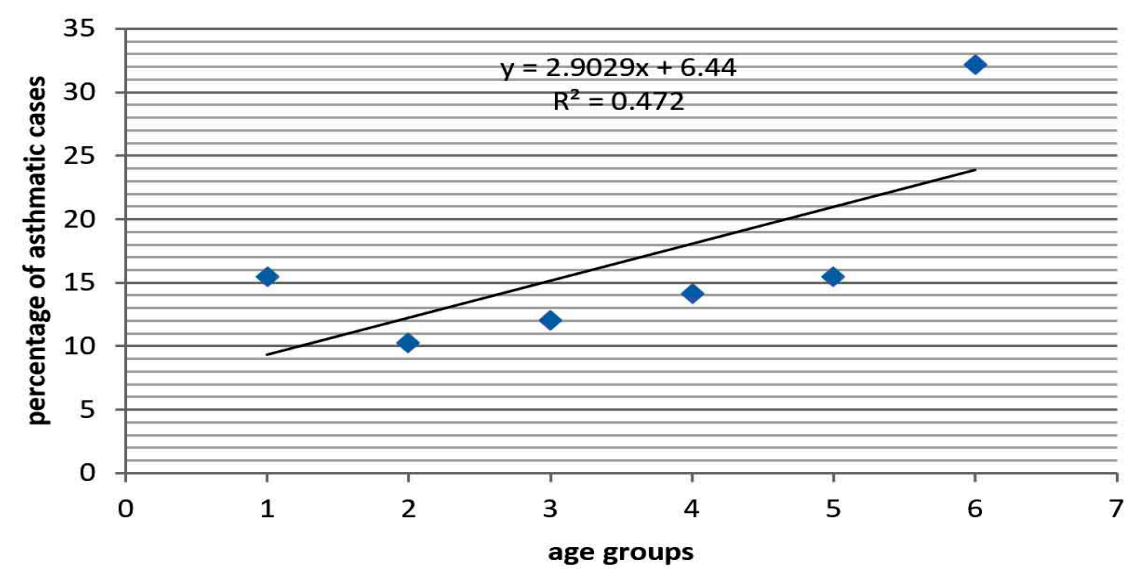

Fig 5. Simple linear regression between age groups and the percentage of patients having asthma 
age groups and asthma $\left(r_{p}=0.687\right)$, but it was not statistically significant $(P=0.132)$, there was a linear regression between the two variable $\left(R^{2}=\right.$ 0.472), ( $y=2.9029 x+6.44)$ as cleared in Fig. 5 .

\section{DISCUSSION}

Data are relatively sparse for the dust fungal spore rate in Al-Najaf governorate. In our study, the total rate of fungal spores showed variation among districts, specifically at Kufa (29\%) which had the highest percentage of fungal spores. The mean total fungal spore concentration in all investigated distract was $\left(\right.$ mean $=1.2578^{\prime} 10^{8}$ $C F U \backslash g$ ) belong to 6 genera. The highest rate of fungal spore type belongs to the species Aspergillus niger (15.7\%), followed by Alternaria (13.8\%), Cladosporium (11\%), penicillium (9.8\%), Mucar (7.5\%) and sporoblomyces (7\%). There was great diversity in the type and rate of fungal spore that found in the outdoor dust across the world. A study performed at Delhi Metropolis reported that Cladosporium represent (25-40\%) from all fungal spore isolates, Aspergillus flavus (10-13\%), Alternaria (11\%) and A.niger (8\%) ${ }^{10}$. The most dominant fungal species were belonging to the genera Cladosporium, Aspergillus and penicillium according to the results of study conducted at New Orleans, Louisiana ${ }^{11}$. Spores concentration depending on environmental factors, such as water, nutrient, temperature and wind $^{12,13}$. We can describe Al-Najaf governorate by benign hot and dry in June, July and August the maximum temperature reaches $46.2^{\circ} \mathrm{C}$, while the temperature ranges from $22^{\circ} \mathrm{C}$ to $32^{\circ} \mathrm{Cin}$ March, April, October, and November, accompanied by an increase in humidity. In our study the logconcentration of fungal spores were increased in March, April, October, and November, on the contrast there was a decrease in spore count through January and February which may be associated with the increase in rainfall and decrease in temperature in these months $10 \div \mathrm{C}$ to $15 \div \mathrm{C}$. The monthly concentration of fungal spore was related to the Climatic factors of the area such as temperature that involved in release of spore and in the fungal colonization processes ${ }^{14}$, which explain the differences in the results of studies that performed in several regions of the world. A study in the Karachi reported a highest fungal spore count was in December at temperature $\left(29^{\circ} \mathrm{C}\right)$, while the lowest spore count was recorded in June at the highest temperature ${ }^{10}$, also other study published from Saudi Arabia and Iran ${ }^{15,16}$ resemblance to Karachi study, while a Turkish study reveal that fungal spore increased in both type and size at meteorological optimal conditions ${ }^{17}$. Asthma is an inflammatory disease of airway. It is a serious public health problem affecting people of all ages; the severity of asthma varies from patients to patients and, even in the same patient during different times, and the reasons for this are not fully understood. Numerous extrinsic factors are known to worsen the symptom of asthma, and the most common factor is the continuous exposure to a triggering allergen ${ }^{5,6}$. The most common allergens implicated are airborne fungal spore. The link between fungi and asthma has been known for centuries, but the correlation between fungal spore concentration and trigger of asthma symptoms has been incompletely explored ${ }^{18}$. The data of this study revealed a strong positive significant correlation between the log-fungal spore concentration and the number of patients have asthma $\left(r_{p}=0.94\right),(P=0.0001)$. Several studies have deal with the concentration of fungal spore and its role in the triggering or worsening the symptom of asthma, some of them reported that the rate of hospital admission for asthma tend to be exceptionally high on days with high total mold spore counts ${ }^{19,20}$, as well as other study reported that asthma symptom PEF was associated with average fungal spore concentration. Furthermore the environmental spore level has been connected with asthma-related deaths ${ }^{21,22}$. Fungi are very common in the environment, and respiratory exposure to airborne spores is almost constant. Fungi can be associated with asthma patients in a number of ways either through inhalation of fungal spores or through fungal sensitization. Fungi have the ability to actively germinate and colonized the respiratory tract. Thus, it is possible that fungi have much greater impact on an individual in terms of triggering host defense against pathogens. Another possible explanation that some fungal antigens generate (auto-immune cross-reactive response) in human because some fungal proteins have a significant homology to human paralogs so that an immune response directed at the fungal protein will also target human counterparts ${ }^{23}$, ${ }^{24}$. This study found an asthma percentage of 
(4.1\%) in Al-Najaf, higher in male $(2.47 \%)$ than female $(1.67 \%)$, the gender differences were statistically non-significant at $P \leq 0.05$. In this study the higher rate of asthma in male approach to the results of a previous study performed in Middle East countries ${ }^{4}$. Others have contradicted these results, they found that asthma was higher in females ${ }^{5,6,25}$. Differences between rural and urban area were statistically non-significant at $P$ $\leq 0.05$ in Al-Najaf, also in Assiut district-Egypt the differences between them were non-significant $(p=0.075)^{26}$. While a study at Uganda clarified a higher rate of asthma at urban compared to rural $(12.99 \% \text { vs } 8.86 \%)^{11}$. Age considered as risk factor associated with asthma according to several studies ${ }^{5,25,27}$. Our results revealed a high percentage of asthma in age group over 50 $(32.2 \%)$, also there are two other peaks in the age groups less than ten years (15.5\%) and forty-one to fifty years $(15.5 \%)$ there was a medium direct correlation $\left(r_{p}=0.687\right)$ and regression $\left(R^{2}=0.472\right)$ towered increasing with age, although there was no significant differences $(p=0.132)$. High asthma prevalence was reported among age group 40-54 years old $(7.7 \%)$ and above 65 years $(12.7 \%)^{27}$. The prevalence of asthma increased with age $(p<0.0001)^{25}$. Otherwise, a study was conducted in the USA showed that the prevalence of asthma in the age group younger than 17 was higher (9.6\%) than those in the age group equal or higher than 18 years $(7.7 \%)^{5}$.

\section{CONCLUSION}

This study showed that there was a variation in the concentration and type of fungal spores in the dust of four districts of AL-Najaf province. The concentrations of fungal spores vary according to months. There is a correlation between the concentration of fungal spores and the number of patients with asthma. Age is one of the influencing factors on asthma. Asthma is a puzzle made up of a number of interconnected and interrelated parts. Different studies are trying to figure out these parts and link them together to see the full picture. It will then be possible to control the spread of the disease.

\section{ACKNOWLEDGMENTS}

None.

\section{CONFLICTS OF INTEREST}

The authors declare that there is no conflict of interest.

\section{FUNDING}

None.

\section{AUTHORS' CONTRIBUTION}

All authors have made substantial, direct and intellectual contribution to the work and approved it for publication.

\section{DATA AVAILABILITY}

All datasets generated or analyzed during this study are included in the manuscript.

\section{ETHICS STATEMENT}

This article does not contain any studies with human participants(data was optioned from hospital recored) or animals performed by any of the authors

\section{REFERENCES}

1. Duhme H, Weiland SK, Keil U. Epidemiological analyses of the relationship between environmental pollution and asthma. Toxicology Letters, 1998; (102): 307-316. https://doi.org/10.1016/S0378-4274(98)00322-1

2. Lai CK, Beasley R, Crane J, Foliaki S, Shah J, Weiland $S$, ISAAC Phase Three Study Group. Global variation in the prevalence and severity of asthma symptoms: phase three of the International Study of Asthma and Allergies in Childhood (ISAAC). Thorax., 2009; 64(6): 476-83. https://doi.org/10.1136/thx.2008.106609

3. Burney PG, Luczynska C, Chinn S, Jarvis D. The European community respiratory health survey. European Respiratory Journal, 1994; 7(5): 954-60. https://doi.org/10.1183/09031936.94.07050954

4. Alavinezhad A, Boskabady $\mathrm{MH}$. The prevalence of asthma and related symptoms in Middle East countries. The Clinical Respiratory Journal. 2018; 12(3): 865-77. https://doi.org/10.1111/crj.12655

5. Akinbami LJ, Moorman JE, Liu X. Asthma prevalence, health care use, and mortality; United States, 20052009.

6. Alavinezhad A, Boskabady MH. The prevalence of asthma and related symptoms in Middle East countries. The Clinical Respiratory Journal, 2018; 12(3): 865-77. https://doi.org/10.1111/crj.12655

7. Achudume AC, Oladipo BO. Effects of dust storm on health in the Nigerian environment. Biology and Medicine, 2009; 1(4): 21-7.

8. Crook B. Inertial samplers: biological perspectives. Bioaerosols handbook, 1995; 1: 247-57.

9. Eduarda W, Heederik D. Methods for quantitative assessment of airborne levels of noninfectious 
microorganisms in highly contaminated work environments. American Industrial Hygiene Association Journal, 1998; 59(2): 113-27. https://doi. org/10.1080/15428119891010370

10. Hasnain SM, Akhter T, Waqar MA. Airborne and allergenic fungal spores of the Karachi environment and their correlation with meteorological factors. Journal of Environmental Monitoring, 2012; 14(3): 1006-13. https://doi.org/10.1039/c2em10545d

11. Kirenga BJ, de Jong C, Katagira W, Kasozi S, Mugenyi L, Boezen M, vander Molen T, Kamya MR. Prevalence and factors associated with asthma among adolescents and adults in Uganda: a general population-based survey. BMC Public Health, 2019; 19(1): 227. https:// doi.org/10.1186/s12889-019-6562-2

12. Gioulekas D, Damialis A, Papakosta D, Spieksma F, Giouleka P, Patakas D. Allergenic fungi spore records (15 years) and sensitization in patients with respiratory allergy in Thessaloniki-Greece. Journal of Investigational Allergology and Clinical Immunology, 2004; 14: 225-31. https://doi.org/10.1046/j.13989995.2003.00312.x

13. Troutt C, Levetin E. Correlation of spring spore concentrations and meteorological conditions in Tulsa, Oklahoma. International Journal of Biometeorology, 2001; 45(2): 64-74. https://doi.org/10.1007/ s004840100087

14. Dixit $A B$, Lewis $W H$, Wedner HJ. The allergens of Epicoccum nigrum link: I. Identification of the allergens by immunoblotting. Journal of Allergy and Clinical Immunology, 1992; 90(1): 11-20. https://doi. org/10.1016/S0091-6749(06)80006-0

15. Al-Suwaine AS, Bahkali AH, Hasnain SM. Seasonal incidence of airborne fungal allergens in Riyadh, Saudi Arabia. Mycopathologia, 1999; 145(1): 15-22. https:// doi.org/10.1023/A:1007073130294

16. Nourian AA, Badali $H$, Khodaverdi $M$, Hamzehei $\mathrm{H}$, Mohseni S. Airborne mycoflora of Zanjan-Iran. International Journal of Agriculture \& Biology, 2007; 9(4): 628-30.

17. Kalyoncu F. Relationship between airborne fungal allergens and meteorological factors in Manisa City, Turkey. Environmental Monitoring and Assessment, 2010; 165(1-4): 553-8. https://doi.org/10.1007/ s10661-009-0966-x

18. Denning DW, O' Driscoll BR, Hogaboam CM, Bowyer P, Niven RM. The link between fungi and severe asthma: a summary of the evidence. Eur. Respir. J., 2006; 27: 615-626. https://doi.org/10.1183/09031936.06.000 74705
19. Salvaggio J, Seabury J, Schoenhardt EA. New Orleans asthma: V. Relationship between Charity Hospital asthma admission rates, semiquantitative pollen and fungal spore counts, and total particulate aerometric sampling data. Journal of Allergy and Clinical Immunology, 1971; 48(2): 96-114. https://doi. org/10.1016/0091-6749(71)90091-1

20. Newson R, Strachan D, Corden J, Millington W. Fungal and other spore counts as predictors of admissions for asthma in the Trent region. Occupation Environ Med., 2000; 57: 786-792. https://doi.org/10.1136/ oem.57.11.786

21. Jenkins PF, Mullins JK, Davies BH, Williams DA. The possible role of aeroallergens in the epidemic of asthma deaths. Clin. Allergy, 1981; 11: 611-620. https://doi.org/10.1111/j.1365-2222.1981.tb02182.x

22. Targonski PV, Persky VW, Ramakrishnan V. Effect of environmental molds on risk of death from asthma during the pollen season. J. Allergy Clin. Immunol., 1995; 95: 955-961. https://doi.org/10.1016/S00916749(95)70095-1

23. Crameri R, Faith A, Hemmann S, et al. Humoral and cell-mediated autoimmunity in allergy to Aspergillus fumigatus. J. Exp. Med., 1996; 184: 265-270. https:// doi.org/10.1084/jem.184.1.265

24. Fluckiger S, Scapozza L, Mayer C, Blaser K, Folkers G, Crameri R. Immunological and structural analysis of IgEmediated cross-reactivity between manganese superoxide dismutases. Int. Arch. Allergy Immunol., 2002; 128: 292-303. https://doi.org/10.1159/000063862

25. Tarraf $\mathrm{H}$, Aydin O, Mungan D, Albader M, Mahboub B, Doble A, Lahlou A, Tariq L, Aziz F, El Hasnaoui A. Prevalence of asthma among the adult general population of five Middle Eastern countries: results of the SNAPSHOT program. BMC Pulmonary Medicine, 2018; 18(1): 68. https://doi.org/10.1186/s12890-0180621-9

26. Abdallah AM, Sanusy KA, Said WS, Mahran DG, Mohamed-Hussein AA. Epidemiology of bronchial asthma among preparatory school children in Assiut district. Egyptian Journal of Pediatric Allergy and Immunology (The), 2012; 10(2).

27. Kim YK, Kim SH, Tak YJ, Jee YK, Lee BJ, Kim SH, Park HW, Jung JW, Bahn JW, Chang YS, Choi DC. High prevalence of current asthma and active smoking effect among the elderly. Clinical \& Experimental Allergy, 2002; 32(12): 1706-12. https://doi.org/10.1046/j.13652222.2002.01524.x 